\title{
Editorial
}

\section{Special issue: Evidence-informed and analytical methods in urban design}

\author{
URBAN DESIGN International (2012) 17, 253-256. doi:10.1057/udi.2012.24
}

The first time I came across the need for analytical tools in urban design was almost 25 years ago when I inherited an urban design project for the regeneration and rehabilitation of the historic centre of the city of Shiraz in Iran. The historic core of the city, more recently engulfed by a large modern city, conveys some 1400 years of history and urban heritage but became badly dilapidated and abandoned for a number of complex reasons. My predecessors on the project had generated layers upon layers of data, from building and physical conditions to social and economic issues. As was customary in the pre-digital era, the data were beautifully presented in hand-painted colour maps nicely decorated with graphic design and calligraphy. What surprised me about the project was that in parallel to collecting and mapping the data another team was already developing solutions and ideas based on the team's assumptions and experiences. When asked why we had collected all the data, the reply was that we had to do it as the contract required us to do so! The reply to my further enquiry into how we should use these data was even more astounding. 'We put the results in a report', I was told! During the remaining course of the project, when we were trying to find solutions for physical transformation with least impact on urban heritage and people's livelihood, I went back to the collected data and tried my best to use it. To a limited extent, even looking at that information was a helpful exercise, but I could not stop wishing for a methodology that could help analyse the data, understand its implications for design and assist in tackling the complex design tasks. It also became absolutely certain to me that all these data and analysis would be meaningless if we could not integrate it directly into a design process. I am sure the frustration that I felt in that project is shared by a large number of other urban designers, who are confident of their skills and intuition, but feel that their work should be informed by more rigorous and objective methods.

The question of design is perhaps one of the mysteries of humankind. There does not seem to be any formula to understand it fully and it is normally left to the talent of the designers to develop their own understanding of it. What distinguishes design from other disciplines such as science and art is that there is always a constituent of intuition and creativity into it, but there is also an element of wisdom and analytical thinking. This dual composition changes according to circumstance and there seems to be a wide spectrum of design types in which design activities vary from purely intuitive tasks, such as designing a decorative object, to a heavily rationalised process, such as the design of an industrial prototype. Urban design, simply defined as the task of shaping the built environment for people, falls inevitably somewhere in the middle of this spectrum, which implies unsurprisingly that we need to sharpen both our intuitive skills and rational thinking to produce good urban design. What is not clear is that these two constituents should be balanced; or more importantly, in which way they should be inherently linked to produce the best results.

There is no intention in this special issue of URBAN DESIGN International to tackle the issue of intuition and creativity in design. This is, if you like, the mysterious part of the design that does not lend itself easily to exploration and investigation. What this issue is trying to do is to approach urban design from a rational standpoint and explore the methods or tools that could enhance the design, without undermining the intuitive aspect of it.

The use of analytical methods in urban design is a relatively new proposition. Although this could be traced back to the work of urban theoreticians, such as Camilo Sitte (1945) and Patrick Geddes (Welter and Whyte, 2003) in the early twentieth century, the analytical approach started to be developed seriously from the mid-twentieth century, when important new urban ideas emerged and urbanists increasingly tried to apply analytical methods and quantitative models to their work. Kevin Lynch (1960) and ChristopherAlexander (1968) were among the pioneers, but analytical thinking in urban design has a much bigger range. 
Apart from the attempts to create an analytical understanding of the city based on mathematical methods and quantitative models, there have also been various transport models, economic models and planning models, which have not been developed specifically for urban design, but have been used in the disciplines that are associated with it. More recently, with the advancement of computer programmes, new techniques of rendering and 3D modelling have emerged that are mainly used in the representation of the design, but are also sometimes used to analyse specific aspects of it. The most recent of these approaches is Parametric Design, which enables designers to change the design parameters and visualise the results dynamically (Motta, 1999). Among the most technical developments in this field, perhaps the invention of Geographical Information Systems holds the most direct influence on analytical approaches in urban planning and transportation (Birkin, 1996).

Despite a big attempt to employ analytical methods and tools in urban design, a major difficulty has persisted: most of these methods cannot easily become an integral part of the urban design process. There are several reasons for this insufficiency, but perhaps prime among them is the lack of an urban theory that can link different aspects of the design into a single framework. This theoretical shortfall creates a gap between the analysis of things and how their manipulation in design could change the impact of the design itself. Furthermore, most current analytical methods are rarely multi-disciplinary and multi-scalar, which restricts their application to particular areas of urban design or planning with very little connection to other disciplines, or to other scales of the urban system. Finally, analytical models that could deal with urban systems, such as transport models, are usually time-consuming, data-intensive and rather expensive to build (Weber and Landis, 2012). With all the challenges involved in using analytical methods in urban design, it is perhaps not surprising that they are not developed rigorously by theoreticians and not used enthusiastically by practitioners.

This special issue presents five articles that have different takes on this problem, ranging from purely theoretical arguments to empirical and experience-based explorations backed by real-life examples. In the first article of the issue, Stephen Marshall takes us back to basics and makes an enquiry into the insufficiency and incoherency of urban design theory in general. This is, in a way, a reflection on the recent critiques of urban design theory, in particular Alexander Cuthbert's (2010) comprehensive assault on traditional urban theory in the past 50 years. Marshall's argument is twofold. First, he argues that urban theory could fall into the boundary of pseudo-science, if it does not have the characteristics of a scientific theory (transparency, hypothesis, validation, ...) or if those characteristics are manipulated to give a scientific appearance to the theory. He warns us about the dangers of using pseudo-science in creating groundings for urbanism. Furthermore, he argues that even if urban theories are more or less scientific, as he finds in the works of four prominent urban theoreticians of the twentieth century (Gordon Cullens, Kevin Lynch, Jane Jacobs and Christopher Alexander), the interpretation and combination of their theories in the field appear more or less as pseudo-science. He argues that more and better urban theories are needed, but admits that urban design also implies a practical design activity, which overlaps with art or technical craft. The implication, he concludes, is the need not just for 'more and better science', but for specifically more 'systematic verification and critical assimilation' of scientific knowledge within urban design theory. While Stephen Marshall's article makes us wary of the shortcomings of urban theories as scientific theories, it somewhat brightens the bleak view of critics such as Cuthbert by suggesting ways of developing an approach that may be generated from dedicated urban design research embedded into the process of urban design.

The second article shifts the discussion a bit closer to the core subject of this special issue: the design thinking. In this article, Olgu Çaliskan highlights the fact that by ignoring the cognitive aspects of design, the urban design field has been relying mainly on early procedural models to bring analytical thinking into design. These models, which have been widely criticised for their shortfalls, do not seem to have fulfilled the task. To set the context, the author begins with a review of the definitions for urban design, which is followed by a comprehensive review of the models of the design process and the transformation of these models in the past century. This is a very helpful exercise in its own right, reminding us about the evolution of the ideas that could be considered as analytical thinking in design. In his view, design models such as the Geddesian survey-analysis-plan model or the analysis-synthesis-decision model of the systems planning approach lack the critical element of conjectureand-test that could be found in both design and 
scientific problem solving. To support this idea and demonstrate how designers practically achieve a design, a detailed review of the design process in two urban design projects is presented, identifying the critical cognitive aspects of design that should be considered in any design approach. By linking the findings of these exercises and the theoretical review of the design methods, the article suggests that a conjecture-analysis-test model is a viable model of urban design.

The third article of this issue begins with discussing the challenges of using analytical methods in urban design and why these methods have not been extensively used before. Through a series of basic propositions about urban design, the article attempts to establish some common ground shared by theoreticians and practitioners, such as: urban design is a process; it is purposeful, with an initiation phase and some form of a product; it involves some degree of problem solving; it cannot be an entirely logical or discursive process, but is capable of being informed by reasoning and analysis. The article then moves on to describe a generic model of urban design that is flexible enough to be used as basis for the development of an analytical urban design model. In this approach, two phases of design generation and design development shape the core of an interactive cycle, which are fed by some forms of a brief, wider socio-economic issues and stakeholder consultation. Each phase includes a series of conjecture-test cycles to generate and develop design solutions. In the analytical urban design approach, two analytical phases are added between the design generation and design development phases. The analysis informs each of these phases, but is also used to assess them. The article then argues that the use of analytical methods in urban design is possible only if these methods are spatial in nature and have the ability to deal with the configurational properties of space. The methods should also be capable of linking the spatial aspect of the analysis directly to social issues and human activities, as well as having the capacity to deal with different scales, or parts and whole, in an urban system. Such characteristics, the article argues, could be found in space syntax, which is a set of theories and methodologies used to analyse the spatial configuration of the urban space and link it with social and human interactions. A full review of the approach is complemented at the end with the review of a sample of three projects, from the scale of urban space to the scale of a large city, in which the methodology has been successfully applied.
The fourth article of this issue addresses a recently developed field in urban design, which is about controlling or manipulating the design parameters to test and visualise the implication of the design: parametric urban design. The authors, Enriqueta Llabres and Eduardo Rico, introduce their specific take on the parametric agenda, Relational Urbanism, as a mechanism for multi-disciplinary engagement in urban design and planning. Relational Urbanism in that sense is a parametric approach, which is not only used by designers to visualise or optimise their design but to communicate it with other disciplines and stakeholders. The proposed methodology aims at integrating site intelligence and architectural inputs, on the one hand, and incorporating inputs from other disciplines that are not generally design oriented, on the other. The approach starts with the definition of a site grid, which reads patterns from existing site conditions and uses them as the basis for an overall site structure. It then moves on to define typological rules, which incorporate smaller-scale concepts and design inputs from the architectural team. The model incorporates two major elements of 'constraint driven solvers', which are basically algorithms for manipulating design parameters and a 'customizable interface', which coordinates 3D input from the previous steps with models from different design expertise. At the end, the authors introduce two large-scale urban projects, in which Relational Urbanism is built as the core methodology.

The last article presents an entirely different issue that is complementary to the issues raised in the first four articles. Bobby Nisha and Margaret Nelson explore the idea of evidence-based decision making (EBDM) in urban design by focusing on urban regeneration projects. The article begins with a review of how purely design-led urban regeneration initiatives in the United Kingdom have come under heavy criticism for their subjective approach and for ignoring the needs of the citizen or end users. Their critical review and analysis of the current approaches to urban design in regeneration concludes that none of these approaches, the subjective design approach, the process approach and the integrated holistic approach, could fulfil the task of a successful urban regeneration without the use of an evidence-based support system in the decision-making process. The article investigates the idea of a knowledge transfer from EBDM to be integrated in the participatory urban design process. The article concludes with a proposed framework for decision making, which is 
influenced by 'realist synthesis' and the domain of 'applied ontology' to optimise stakeholder's participation and produce well-informed design. The proposed model has yet to be assessed in future research, but the authors clearly make a case for using these methods in urban design process.

The field of analytical and evidence-based urban design has been dormant after the criticism of the early approaches. However, it seems that it has come back with new ideas that are sorely needed. It is hoped that this special issue of URBAN DESIGN International could invigorate the field and generate further debates to inform urban design in future.

\section{References}

Alexander, C. (1968) Notes on the Synthesis. Cambridge, MA: Harvard University Press.
Birkin, M. (1996) Intelligent GIS: Location Decisions and Strategic Planning. Cambridge, UK: GeoInformation International.

Cuthbert, A. (2010) Whose urban design? Journal of URBAN DESIGN 15(3): 443-448.

Lynch, K. (1960) The Image of the City. Cambridge, MA: MIT Press.

Motta, E. (1999) Reusable Components for Knowledge Modelling: Case Studies in Parametric Design Problem Solving. Amsterdam, the Netherlands: IOS Press.

Sitte, C. (1945) The art of Building Cities: City Building According to Its Artistic Fundamentals. New York: Hyperion Press.

Weber, R. and Landis, J. (2012) Modelling urban systems. In: R. Weber and R. Crane (eds.) The Oxford Handbook of Urban Planning. Oxford: Oxford University Press.

Welter, V.M. and Whyte, I.B. (2003) Biopolis: Patrick Geddes and the City of Life. Cambridge, MA: MIT Press.

Kayvan Karimi

Bartlett School of Graduate Studies, London, UK Space Syntax, Brownlow Mews, London, UK E-mails: k.karimi@ucl.ac.uk; k.karimi@spacesyntax.com 